\title{
Treatment- and diagnosis-related benchmarking of population groups in Austria. A dynamic information tool Nina Pfeffer* and Alexander Ganjeizadeh-Rouhani
}

\author{
Address: Main Association of Austrian Social Security Institutions, Kundmanngasse 21, Vienna, 1030, Austria \\ Email: Nina Pfeffer* - nina.pfeffer@hvb.sozvers.at \\ * Corresponding author
}

from 24th Patient Classification Systems International (PCSI) Working Conference Lisbon, Portugal. 8-II October 2008

Published: 27 November 2008

BMC Health Services Research 2008, 8(SuppI I):A4 doi:I0.I 186/I472-6963-8-SI-A4

This abstract is available from: http://www.biomedcentral.com/I472-6963/8/SI/A4

(c) 2008 Pfeffer and Ganjeizadeh-Rouhani; licensee BioMed Central Ltd.

\section{Introduction}

In the past, a nationwide analysis of hospital data has not been realisable for Austrian sickness funds due to the federal character of the Austrian healthcare system. However, decision makers in the Social Security and Health Care Platforms need this nationwide analysis to gain the information and knowledge for governing and planning the healthcare system.

In order to supply support for this decision-making process, the Main Association of the Austrian Social Security Institutions - an umbrella organisation of all Social Security Funds - started to develop a software-based benchmarking system that allows a comparative analysis of the hospitalization rate, as well as the related diagnoses and medical treatments for all Austrian regional population groups.

For the analysis, we use the hospital data, which is being reported by the public hospitals to the Ministry of Health, and provide the results via an OLAP database and webbased standard reports on the Social Security Intranet.

\section{Methods}

Working with treatment and diagnosis data, we evaluate the frequency of hospital stays for the regional population groups in Austria. The performed analysis has its focus on the patient's place of residence and does not account for the location of the treating hospital. As a result, we analyze the hospital treatment data for a regional population no matter in which Austrian hospital the treatment was given.

Treatment and diagnosis data are calculated per 10,000 inhabitants of a population, and the figures are related to the Austrian average as a benchmark. The result is the proportional deviation of the regional number compared to the Austrian average of the reference number. Results can be calculated allowing for age standardization.

The underlying software tool allows a systematic calculation for each procedure or diagnosis listed in the official reimbursement catalogue. In addition, the aggregation of related procedures or diagnoses is possible.

The calculation can be parameterized; moreover, the parameters can be combined and are automatically considered by the software program when calculating the reference numbers.

The results are presented via tables and diagrams or a geographic information system (GIS).

The evaluation process is standardized and mapped with business modeling software. The process helps the user to detect inappropriate healthcare services - on the level of single procedures and diagnoses or on an aggregated level - for regional population groups in a systematic way, and to compare the results to other regional populations. Moreover, it supports the user in identifying the treating 
hospitals and in displaying the regions where treatment is provided by a particular hospital.

\section{Results}

We developed a process-oriented, software-based and dynamically parametrizable model to systematically quantify regional imbalances of healthcare services provided by hospitals for the Austrian population. Assuming that the provision of healthcare in Austria is adequate and equally distributed on a national level, the provision of hospital treatments for every regional population is reported corresponding to the Austrian average.

This model also allows us to identify potential medical causes, and problems that arise because of the way the Austrian healthcare system works. It can be accessed via a web-based software tool by all Social Security Funds.

\section{Conclusion}

The model can help decision makers of the Austrian Social Security and other governmental bodies to identify imbalances in healthcare provision and to reveal fields of activity for governing and planning measures. Especially with respect to the ongoing discussion on healthcare reform, accompanied by a discussion on efficiency and costs of provision structures, results like the ones of this model will be needed for developing steering measures and assessing the efficacy of the action taken.

Publish with Biomed Central and every scientist can read your work free of charge

"BioMed Central will be the most significant development for disseminating the results of biomedical research in our lifetime." Sir Paul Nurse, Cancer Research UK

Your research papers will be:

- available free of charge to the entire biomedical community

- peer reviewed and published immediately upon acceptance

- cited in PubMed and archived on PubMed Central

- yours - you keep the copyright

Submit your manuscript here:

http://www.biomedcentral.com/info/publishing_adv.asp 